\title{
Unilateral Isolated Proximal Femoral Focal Deficiency in an Egyptian Infant and Review of Literature
}

\author{
Manal M. Thomas ${ }^{1}{ }^{10}$ Angie M.S. Tosson ${ }^{2}$ Mohamed B. Taher ${ }^{1}$ \\ ${ }^{1}$ Human Genetics and Genome Research Division, Clinical Genetics \\ Department, National Research Centre, Egypt \\ ${ }^{2}$ Department of Pediatrics, Faculty of Medicine, Cairo University, Egypt \\ Address for correspondence Manal M. Thomas. MD, PhD, 33rd El \\ Bohouth Street, Dokki, Giza 12622, Egypt \\ (e-mail: nula_m@hotmail.com).
}

J Child Sci 2020;10:e126-e133.

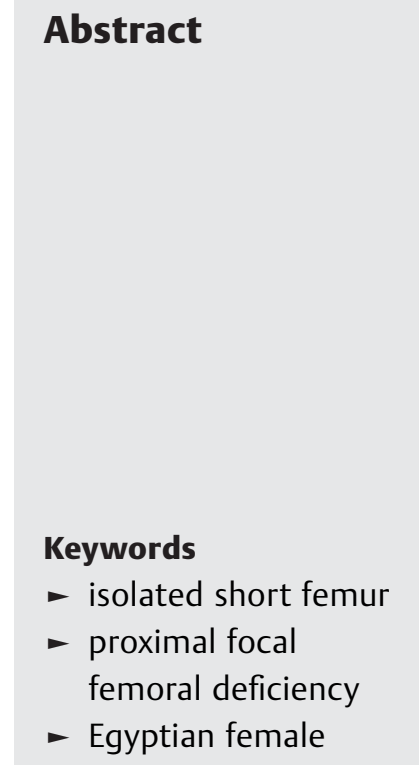

Proximal femoral focal deficiency (PFFD) is a rare congenital anomaly of the femur ranging from mild shortening to total agenesis. If left untreated, it could lead to impaired child growth, abnormal gait, vertebral abnormalities, cosmetic problems, and behavioral changes. We report on an Egyptian female, presenting to us at the age of 15 days with a short left lower limb. Both upper limbs and the right lower limb were normal and she was not dysmorphic. The skeletal survey showed an isolated short left femur. At the age of 11 months, clinical reexamination confirmed left femur shortening. Echocardiogram and abdominal sonography revealed no abnormality. Magnetic resonance imaging (MRI) of the pelvis and lower limbs revealed isolated left proximal femoral focal deficiency. Her developmental milestones were normal. She was referred to pediatric orthopaedics for early intervention and proper management. To our knowledge and after reviewing the literature, this patient represents the first case of unilateral isolated proximal focal femoral deficiency in Egypt. In conclusion, PFFD diagnosis needs a systemic skeletal-facial-genital phenotyping to differentiate from overlapping genetic disorders. Early diagnosis and radioimaging are highly important for proper management.

\section{Introduction}

Proximal femoral focal deficiency (PFFD) is a rare congenital defect of the proximal femur, which manifests as hypoplasia of the femur resulting in a shortening of the affected limb. The mode of inheritance of PFFD is sporadic; however, few familial cases were reported. ${ }^{1}$ PFFD incidence is 1.1 to 2 in 100,000 live births with unilateral limb affection in 85 to $90 \%$, although bilateral PFFD may occur. ${ }^{2}$ PFFD is caused by the deficient formation of the subtrochanteric part of the femoral shaft affecting its length with subsequent deformity ranging from mild femoral shortening to absent femur and acetabulum. ${ }^{3}$

X-rays are useful for diagnosis. Various PFFD classifications have been proposed. However, the most commonly used classification is that described by Aitken and modified by Amstutz, which is based primarily on X-ray data of the

received

July 4, 2020

accepted

August 15, 2020
DOI https://doi.org/

10.1055/s-0040-1716918. ISSN 2474-5871. presence of the femoral head, a stable hip joint, or acetabular hypoplasia and classifying the abnormality in A to D types according to severity. ${ }^{4,5}$

The condition may be accurately classified at the age of 1 or 2 years. Magnetic resonance imaging (MRI) is used for definitive subtype classification, which is needed for accurate prognosis and management. ${ }^{6}$ Congenital hypoplasia of the femur is part of several medical conditions. However, PFFD should be differentiated from the following three overlapping genetic syndromes: (1) femoral hypoplasia-unusual facies syndrome (FH/UFS), also called femoral-facial syndrome (FFS; MIM: 134780); (2) femur/ fibula/ulnar hypoplasia syndrome (FFU: MIM: 228200); and (3) limb/pelvis-hypoplasia/aplasia syndrome (LPHA), also called Al-Awadi/RAAS-Rothschild's syndrome (AARRS; MIM: 276820). ${ }^{4,5}$
Copyright $\odot 2020$ Georg Thieme Verlag License terms KG Stuttgart · New York 
Here, we report a female infant with proximal focal $\mathrm{FH}$ and differentiate her clinical manifestations from other genetic and nongenetic conditions. A short review of the PFFD classification and future counseling is also presented.

\section{Patient and Results}

A 15-day old, Egyptian girl infant patient presenting with a short left lower limb was referred to the Developmental Assessment and Genetic Disorders Clinic, National Research Centre (NRC), for diagnosis and genetic counseling. This research was reviewed and approved by the Research Ethics of the National Research Centre according to the "World Medical Association Declaration of Helsinki" in 1995 (as revised in Seoul 2008) and written informed consent was obtained.

The infant was the third child of healthy nonconsanguineous parents. At her birth, the father and mother were 33 and 25 years, respectively. The mother did not take any medications, was not diabetic, and did not suffer from any other medical conditions all through her pregnancy. The pregnancy period was uneventful and delivery was by Caesarian section due to a contracted pelvis at 39 weeks of gestation. The proband's older sister and brother were healthy. The mother was first prenatally examined at the prenatal and fetal diagnosis clinic when she was at her 8th to 9th weeks' gestation. She was asked to come back for regular visits to follow-up during the pregnancy but she discontinued the visits. After delivery of the baby, she came for clinical assessment, diagnosis, and genetic counseling.

On examination, the index case height, weight, and head circumference were $50 \mathrm{~cm}$ (mean), $3.4 \mathrm{~kg}$ (mean), $33 \mathrm{~cm}(-0.8$ standard deviation [SD]), respectively. She was not dysmorphic. Chest, heart, abdominal, neurological, and genital examination showed no abnormality. Both upper limbs and right lower limb were normal. The left lower limb was short. The left thigh was bulky and flexed. The left hip joint was laterally rotated and abducted ( - Fig. $\mathbf{1}$ ). The skeletal survey showed a hypoplastic left femur with a relatively shallow left acetabulum. An Echocardiogram detected small patent foramen oval (PFO). Chromosomal analysis by G-banding technique revealed normal female karyotype (46, XX).

Reexamination at the age of 11 months showed that her height, weight, and head circumference were $73 \mathrm{~cm}$ (mean, SD), $9.2 \mathrm{~kg}$ (-0.5 SD), $45.6 \mathrm{~cm}$ ( $-0.7 \mathrm{SD})$, respectively. Chest, heart, abdominal, neurological, and genital examinations came out normal. Echocardiogram and the abdominal ultrasound revealed no abnormality. The patient's developmental milestones were assessed using Bayley's scales of infant and toddler development (third edition) and were normal Developmental Quotient $(D Q=82)$. Her left lower limb was short (-Fig. 1). Plain X-ray of the pelvis and both lower limbs showed a short left femur, normal tibia and fibula, and normal right lower limb long bones (-Fig. 2). MRI of the pelvis and both hip joints showed the following: left small femoral head, markedly shortened left femur with subtrochanteric varus deformity, well-developed left acetabulum, acartilagenous plate connecting the distal femur with the femoral neck and head, intact left femoroacetabular joint, and normal size left upper thigh muscles (-Fig. 3). These findings classified the patient's PFFD as Aitken's B mild dysplasia. ${ }^{4}$ Ophthalmological and audiological examination showed no abnormality. Auditory brain response (ABR) and electroencephalogram (EEG) examinations were normal.

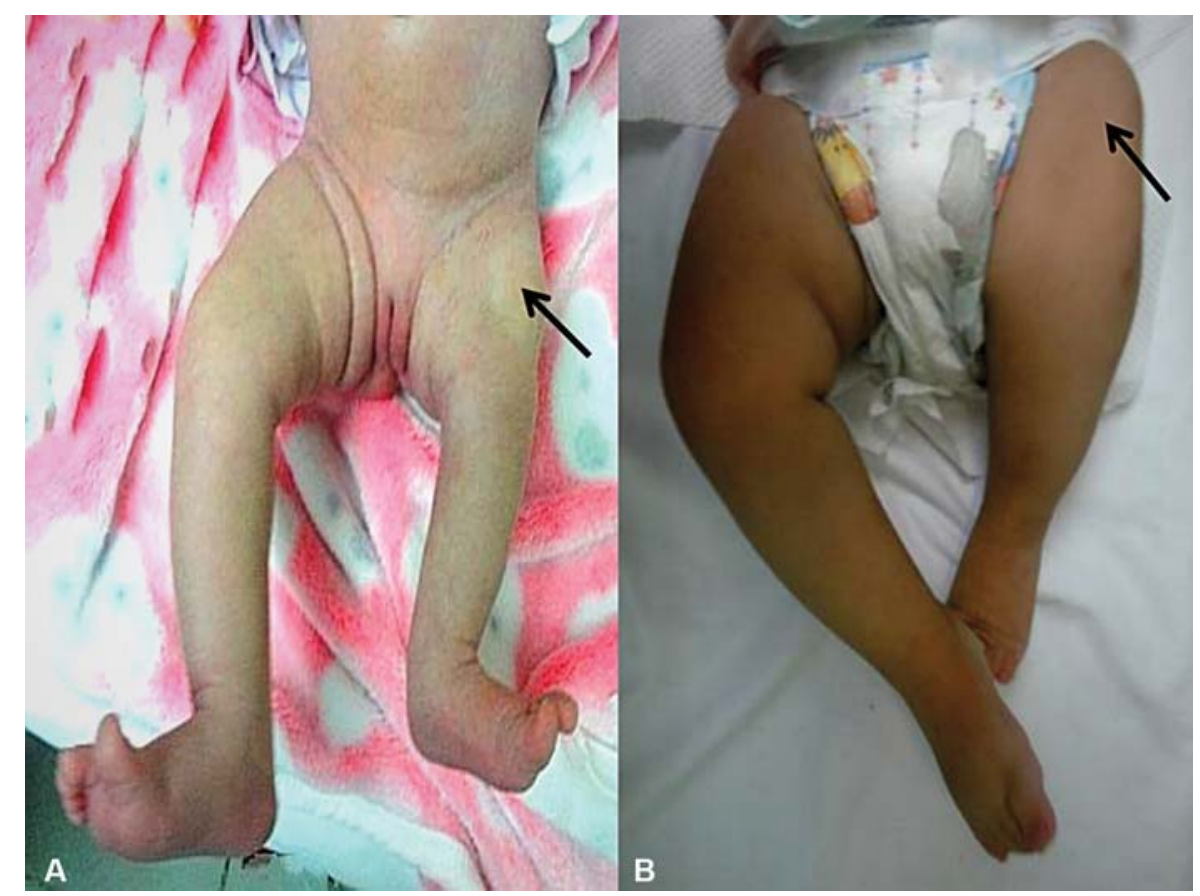

Fig. 1 (A) The patient at 15 days showing short left lower limb. The left thigh is bulky with flexion, lateral rotation and abduction at the left hip joint (arrow). (B) The patient at 11 months showing the same feature (short left lower limb and short externally rotated left thigh (arrow) (lower limb discrepancy). 


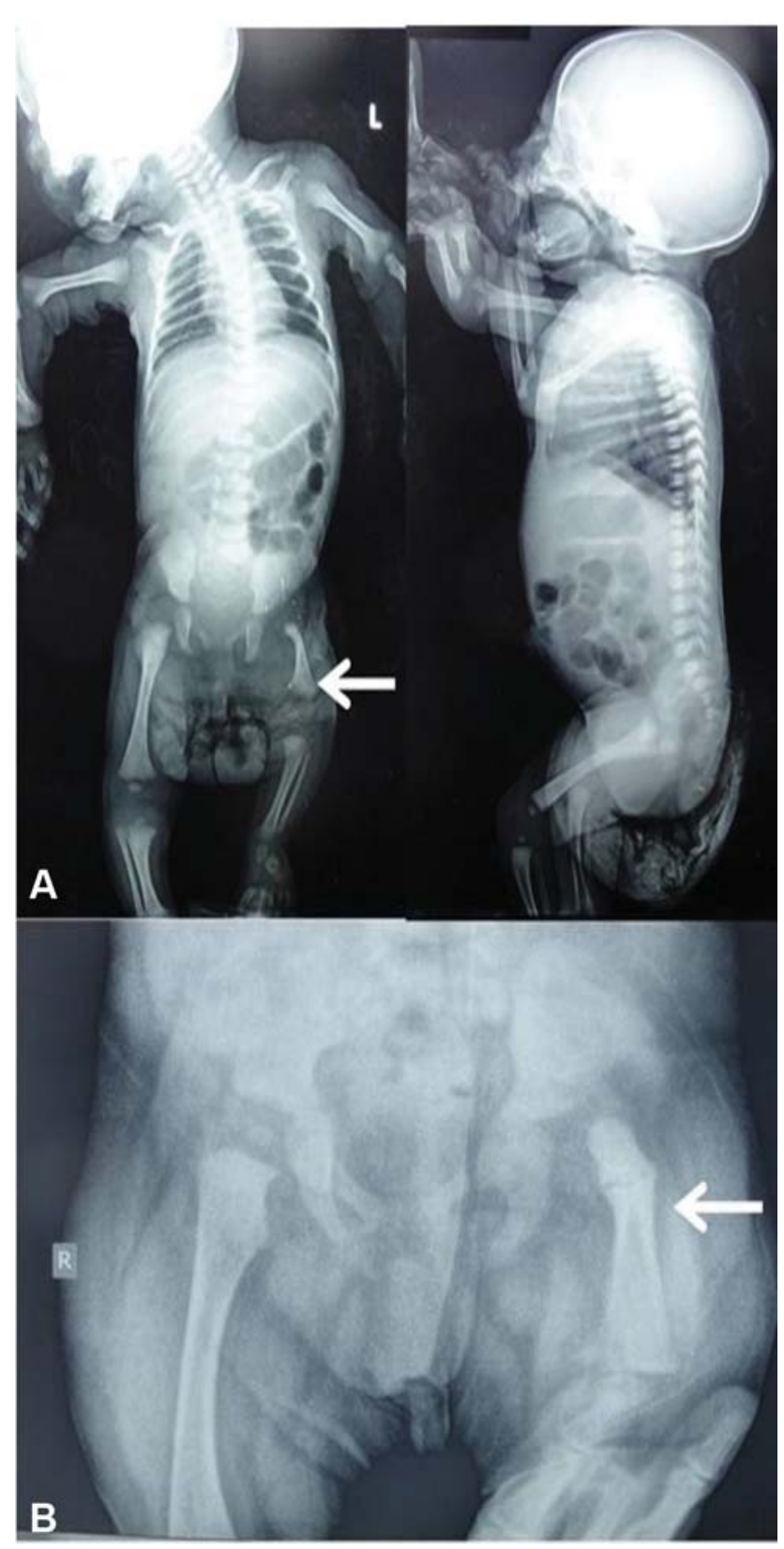

Fig. 2 (A) A plain X-ray anteroposterior view of whole body of the patient at 15 days showing hypoplasia of left femur (arrow) with bowing of residual shaft and symmetrical length of both tibiae and fibulae, with normal appearance and texture of all the other skeletal bones. (B) A plain X-ray lateral view of whole body of the patient at 15 days showing normal appearance and texture of all the other skeletal bones. (C) A plain X-ray anteroposterior view of pelvis and both lower limbs of the patient at 11 months showing the same skeletal changes reported at 15 days of age (-Fig. 2A).

- Table 1 summarizes the findings in our patient compared with three genetic syndromes.

\section{Discussion}

PFFD is a congenital developmental disorder of the subtrochanteric region of the femur with variable degrees of shortening of the proximal femoral segment leading to hip deformity and dysfunction of the affected lower limb. ${ }^{7}$
Full pedigree analysis revealed unaffected nonconsanguineous parents with negative family history. This was in agreement with previous studies reporting the sporadic inheritance pattern of PFFD with no parental age effect. ${ }^{1}$

PFFD cases commonly present with limb discrepancies and short flexed, abducted, and externally rotated thigh. ${ }^{8,9}$ Our index patient presented with left lower limb shortening with strikingly short flexed, abducted, and externally rotated thigh. Clinical presentation of PFFD could be significantly variable depending on the degree of $\mathrm{FH}^{10}{ }^{10}$ Bilateral femoral shortening is less commonly seen in cases with PFFD with varying degrees of severity. ${ }^{11}$ PFFD has a wide range of presentation starting from a mild degree of shortening to severe hypoplasia of the acetabulum, femoral head, and femoral shaft. ${ }^{8}$ Our index patient showed severe shortening (more than $50 \%$ of normal length) of the left femur on plain Xray. Also, she exhibited subtrochanteric varus deformity with a well-developed left acetabulum and intact left femoroacetabular joint. This could be attributed to a failure of formation due to damage of the neural crests of L4 and L5 very early in embryonic life resulting in a defective proliferation of chondrocytes with subsequent immaturity of the proximal femoral growth plate. ${ }^{7}$ Embryologically, Irx3 and Irx 5 (Irx3/5) genes are essential in initiating the limb bud to specify progenitors of the femur, tibia, and digit 1 . Limb bud initiation is negatively regulated by sonic hedgehog (Shh) signaling. ${ }^{12}$ Premature activation of Shh signaling during the early limb development phase disturbs the establishment of limb progenitors and signaling centers affecting the normal outgrowth of the limb. ${ }^{13}$

Several classification systems described congenital anomalies of the femur based on radiological findings. Aitken's is the most used. Other classifications provided detailed radiologic descriptions of the various forms of PFFD. ${ }^{5,14,15}$ It is worthy to mention that these classifications are mainly descriptive and do not help in determining the final femoral morphology or treatment strategies which stimulated Paley to publish a classification that is more focused on pathologic factors determining management strategies. ${ }^{16}$ Each type in the Paley classification has a different operative treatment. The Paley classification system is based on the degree of deficiency to design surgical reconstruction strategies. - Table 2 summarizes the most common classifications. Since the diagnosis and classification of PFFD was mainly based on radioimaging ${ }^{17}$; our case was classified according to Aitken ${ }^{4}$ as class $\mathrm{B}$ by pelvic MRI, and was classified according to Paley as type $1 \mathrm{~B} .{ }^{16}$ Accordingly, radiological assessment is mandatory for accurate classification and future management which should be started as early as possible to allow for the best clinical outcome. ${ }^{6}$ Different studies demonstrated the importance of MRI in accurate diagnosis for proper management of cases with PFFD. ${ }^{8,9,18,19}$

Our index patient did not have antenatal care, although antenatal ultrasound findings of similar cases were reported in many studies between 18 and 32 weeks' gestation. ${ }^{1,2,7,11,20-22}$ Kudla et $\mathrm{al}^{23}$ reported a fetus as early as the 12 th week of gestation whose ultrasound evaluation detected lower limb asymmetry and was diagnosed with 


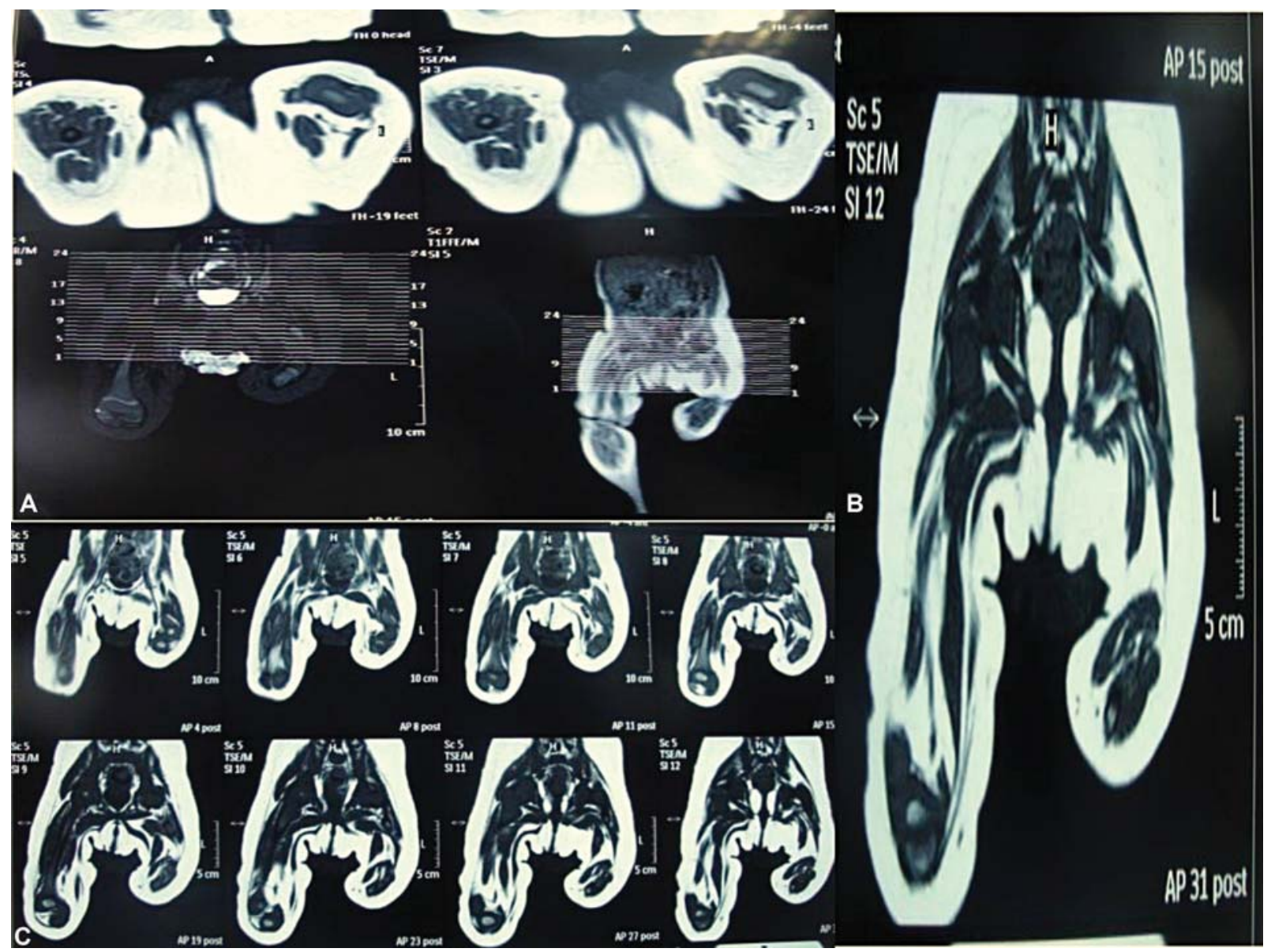

Fig. 3 (A-C) MRI of pelvis, right and left femur of the patient at 11 months showing hypoplasia of left femur. MRI, magnetic resonance imaging.

Table 1 Summary of our patient data with comparison to clinically overlapping genetic syndromes

\begin{tabular}{|c|c|c|c|c|c|}
\hline & Proband & FHUFS & FFU & LPHA & PFFD \\
\hline Other known name for condition & - & FFS & - & $\begin{array}{l}\text { Al-Awadi/ } \\
\text { RAAS_Rothchild } \\
\text { syndrome (AARS) }\end{array}$ & - \\
\hline OMIM number & - & 134780 & 228200 & 276820 & - \\
\hline Mode of inheritance & Unknown & Unknown & Unknown & AR & Unknown \\
\hline Dysmorphic facies & - & + & - & + & - \\
\hline Hypoplastic femur & + (unilateral) & + (bilateral) & + (unilateral) & + (bilateral) & + (unilateral) \\
\hline Pelvic dysplasia & - & + & - & + & - \\
\hline Hypoplastic/absent fibula & $-1-$ & $+1-$ & $+1-$ & $+1+$ & $-1-$ \\
\hline Club foot & - & + & - & - & - \\
\hline Lumbar spine abnormalities & - & + & - & - & - \\
\hline Short/absent humerus & $-1-$ & $+1-$ & $+1+$ & $+1+$ & $-1-$ \\
\hline Hypoplastic/absent ulna & $-1-$ & $-1-$ & $+1-$ & $+1+$ & $-1-$ \\
\hline Finger/toe anomalies & - & - & + & $+1+$ & - \\
\hline Skull defects & - & - & - & + & - \\
\hline Thoracic cage deformity & - & - & - & + & - \\
\hline Genitourinary anomalies & - & + & - & + & - \\
\hline
\end{tabular}

Abbreviations: AR, autosomal recessive; FFU, femur/fibula/ulnar hypoplasia; FHUFS, femoral hypoplasia-unusual facies syndrome; LPHA, limb/pelvis-hypoplasia/aplasia syndrome; OMIM, online Mendelian inheritance in man; PFFD, proximal femoral focal deficiency. Note: $(+)$ represents present and $(-)$ represents absent. 


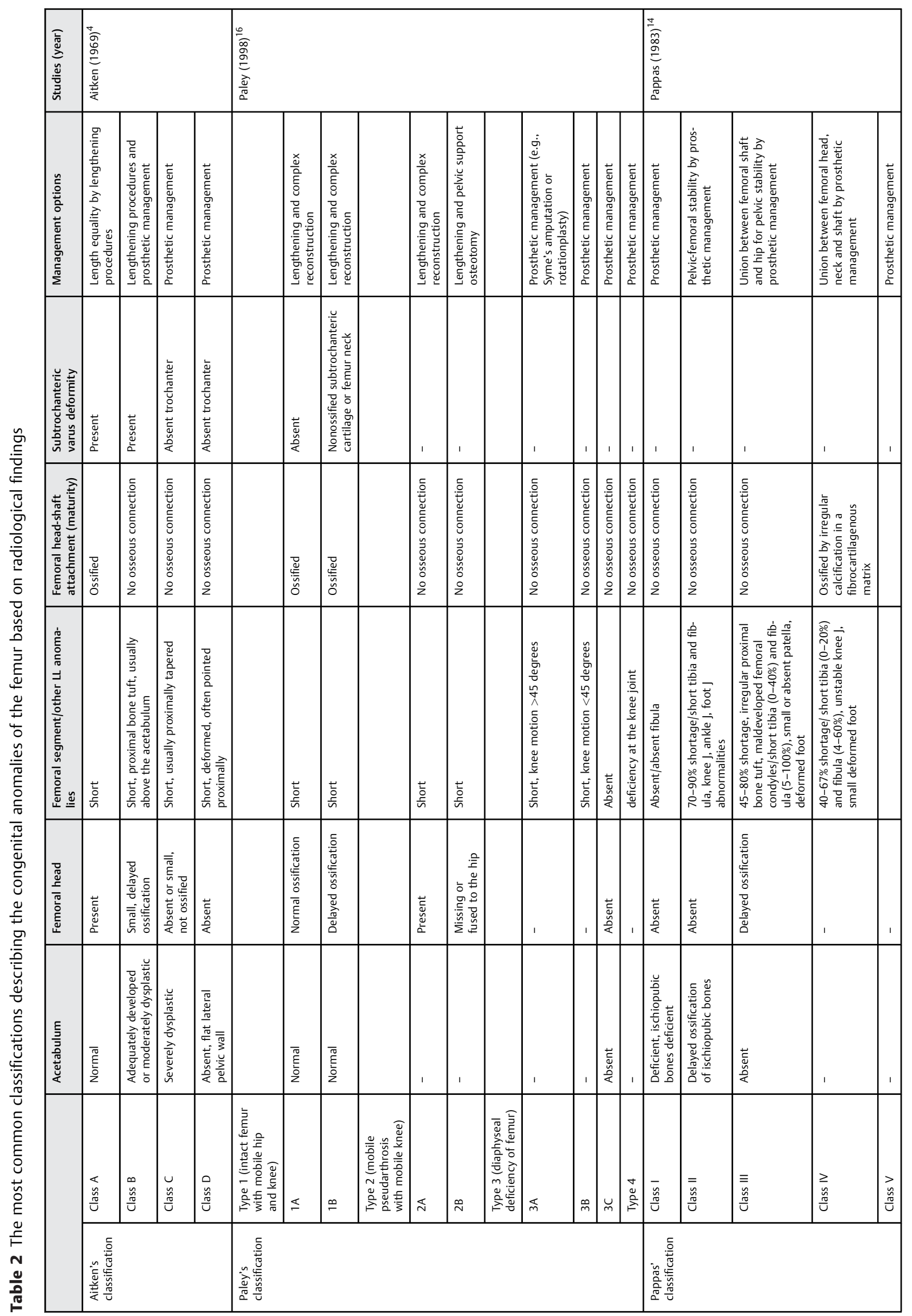




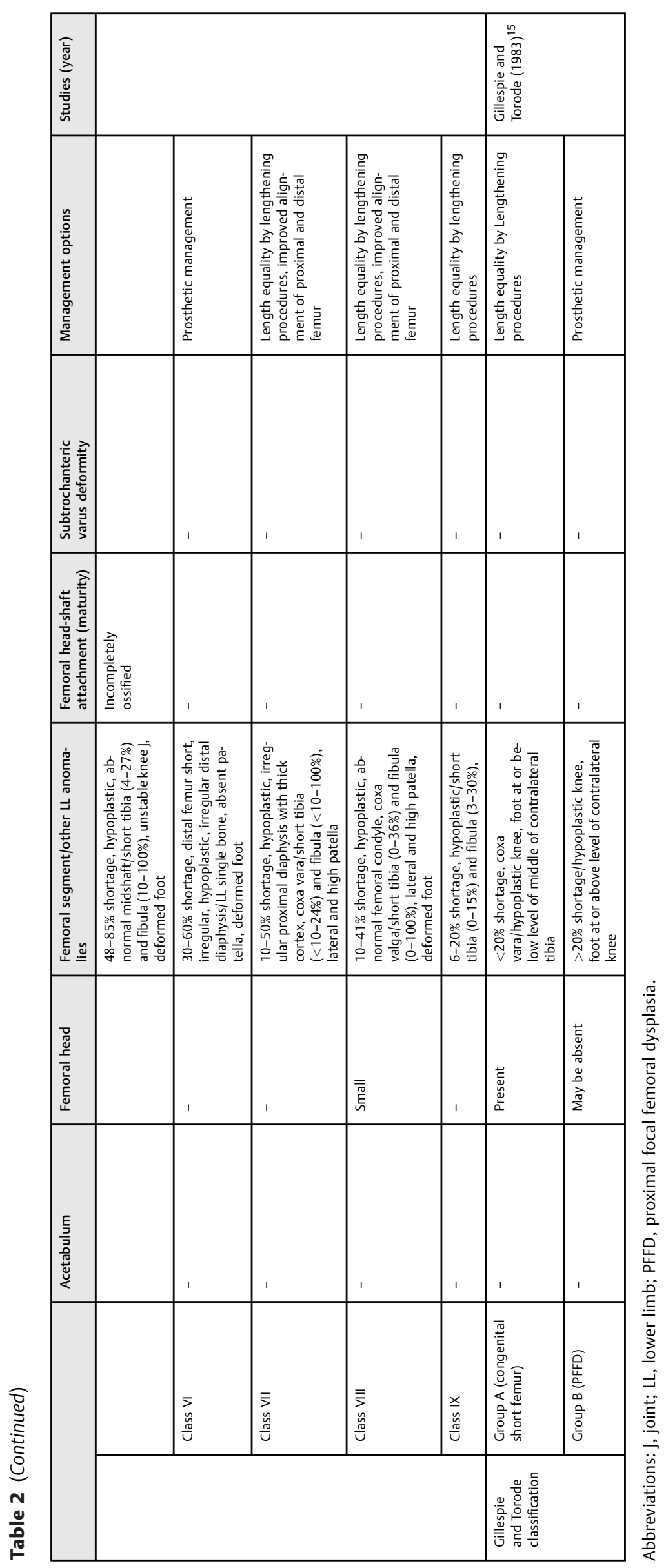


isolated PFFD. Almost all cases of PFFD reported to date are in young children or diagnosed during the antenatal period. Also in the current literature, few cases of PFFD were diagnosed in adulthood. Özdemir et $\mathrm{al}^{24}$ reported isolated unilateral PFFD presenting in a young woman.

Many risk factors for PFFD were documented in the literature such as hypoxia, ischemia, diabetes mellitus, irradiation, chemical toxins, microbiological agents, and hormones. Other risk factors included mechanical injuries, thermal injuries, thalidomide exposure, and fetal trauma between the 4th and 8 th weeks of gestation. ${ }^{3,7}$ However, none of these factors were present in the patient or her mother. This was in agreement with Uduma et $\mathrm{al}^{25}$ who did not report any risk factors in their study on two patients with PFFD.

Our case was not associated with other congenital skeletal abnormalities. Previous studies reported the association of other skeletal abnormalities with PFFD in approximately 30 to $60 \%$ of the reported cases like fibular agenesis (22\%), club foot deformity (17\%), and bowed tibia (17\%). ${ }^{11}$ Other described skeletal anomalies included congenital talipes equinovarus, hypoplastic patella, oligodactyly, absence of knee cruciate ligaments, and spinal deformity. $18,21,26,27$

In addition, PFFD could be a finding of other genetic syndromes including FH-unusual facies syndrome, femur/fibula/ ulnar hypoplasia syndrome, and limb/pelvis-hypoplasia/aplasia syndrome as summarized in - Table 1. FH-unusual facies syndrome is characterized by unilateral or bilateral $\mathrm{FH}$ and dysmorphic facies in the form of micrognathia, cleft lip and/or palate, upward slanting of the palpebral fissure, short nose with a broad tip, thin upper lip, and long philtrum. ${ }^{22,28}$ As for femur/ fibula/ulnar hypoplasia syndrome; there is an affection of the femur, fibula, and ulna with finger and/or toe anomalies. The affection is more common on the right side and is encountered more frequently in males. ${ }^{22,29}$ The limb/pelvis-hypoplasia/ aplasia syndrome usually affects both upper and lower limbs with pelvic affection and characteristic facies in the form of large dysplastic ears and high palate. ${ }^{30}$ On the contrary, PFFD only presents with short and unequal femur length excluding its association with other genetic syndromes.

Management of PFFD requires integration between prosthetists, pediatric orthopaedic surgeons, and physical therapists to equalize the limb length as early as the child starts walking (at 1-2 years). ${ }^{31}$ Management mainly depends on the degree of severity, the association of other anomalies, and lower limb discrepancy when achieving maturity. The predicted length of the femur at maturity and pelvic-femoral stability are the most essential factors in determining treatment plans for PFFD. Treatment aims at the establishment of the hip stability, lengthening of the affected lower limb, and accomplishment of the normal anatomic alignments. ${ }^{27}$ Secondary deformities are not commonly associated with PFFD patients except for the development of asymmetric lower limbs. Consequent negligence and/or delay in management interference could result in functional impairment and scoliosis causing back pain. ${ }^{2}$ Patients with PFFD class-A encounter very few side effects, while patients with classes B, C, and D usually need surgical correction. Therefore, our index case that was classified as class B may require surgical procedure steps to achieve leg lengthening and hip-joint stability and according to the Paley classification, our case that was classified as type 1B could be managed with complex reconstruction surgery. She was referred to a pediatric orthopaedic who examined her and recommended reevaluation at an older age ( $>$ year), and after achieving adequate standing to decide on the proper interference according to her orthopaedic findings. He also described to her especial crutches to achieve equal leg lengths and allow optimum standing and walking to be followed by multiple staged lengthening procedures using extension prosthesis to be started at 3 years of age depending on the predicted limb discrepancy $(<20 \mathrm{~cm})$ at maturity and functioning knee, ankle, and foot, and good muscle power. ${ }^{31,32}$ If the predicted discrepancy is more than $20 \mathrm{~cm}$, or if the child is not suitable for limb lengthening, ambulation with surgical prosthesis and reconstruction surgeries should be considered. Valgus osteotomy, knee arthrodesis, distal femoral epiphysiodesis, the van Nes rotationplasty, the Syme amputation, and femoral lengthening operations are the most commonly used procedures. Many studies revealed a good long-term prognosis after surgical orthopaedic correction. $8,10,17$

Prenatal diagnosis of PFFD is helpful to early recognize the deformity and provide parents and physicians with useful information on management and future therapeutic planning.

\section{Conclusion}

Proximal femoral focal deficiency (PFFD) is one of the commonest causes of congenital lower extremity shortening. Conventional radiographic evaluation by X-ray, ultrasound, and MRI are considered as the main diagnostic imaging modality for diagnosis and classification. They also help to put suitable management plans that positively affect the prognosis and long-term prospects of the patients.

\section{Conflict of Interest}

None declared.

\section{References}

1 Mailath-Pokorny M, Timor-Tritsch IE, Monteagudo A, Mittal K, Konno F, Santos R. Prenatal diagnosis of unilateral proximal femoral focal deficiency at 19 weeks' gestation: case report and review of the literature. Ultrasound Obstet Gynecol 2011;38(05):594-597

2 Doğer E, Köpük SY, Cakıroğlu Y, Cakır O, Yücesoy G. Unilateral isolated proximal femoral focal deficiency. Case Rep Obstet Gynecol 2013;2013:637904

3 Filly AL, Robnett-Filly B, Filly RA. Syndromes with focal femoral deficiency: strengths and weaknesses of prenatal sonography. J Ultrasound Med 2004;23(11):1511-1516

4 Aitken GT. Proximal femoral focal deficiency: definition, classification and management. In: Aitken GT, eds. Proximal Femoral Deficiency: A Congenital Anomaly. Washington, DC: National Academy of Sciences; 1969:1

5 Amstutz HC. The morphology, natural history, and treatment of proximal femoral deficiency. In: Aitken GT, eds. Proximal Femoral Deficiency: A Congenital Anomaly. Washington, DC: National Academy of Sciences; 1969:50

6 Bernaerts A, Pouillon M, De Ridder K, Vanhoenacker F. Value of magnetic resonance imaging in early assessment of proximal femoral focal deficiency (PFFD). JBR-BTR 2006;89(06):325-327 
7 Gerscovich EO, Sekhon S, Loehfelm TW, Greenspan A. Fetal ultrasound: Early diagnosis and natural evolution of proximal femoral focal deficiency. J Ultrason 2017;17(71):294-298

8 Bedoya MA, Chauvin NA, Jaramillo D, Davidson R, Horn BD, HoFung V. Common patterns of congenital lower extremity shortening: diagnosis, classification, and follow-up. Radiographics 2015;35(04):1191-1207

9 Kakarla S. Proximal femoral focal deficiency (PFFD) imaging spectrum. J Med Sci Res 2015;3:90-93

10 Westberry DE, Davids JR. Proximal focal femoral deficiency (PFFD): management options and controversies. Hip Int 2009; 19(Suppl 6):S18-S25

11 D'Ambrosio V, Pasquali G, Squarcella A, et al. Prenatal diagnosis of proximal focal femoral deficiency: Literature review of prenatal sonographic findings. J Clin Ultrasound 2016;44(04):252-259

12 Li D, Sakuma R, Vakili NA, et al. Formation of proximal and anterior limb skeleton requires early function of Irx3 and Irx5 and is negatively regulated by Shh signaling. Dev Cell 2014;29 (02):233-240

13 Zhulyn O, Li D, Deimling S, et al. A switch from low to high Shh activity regulates establishment of limb progenitors and signaling centers. Dev Cell 2014;29(02):241-249

14 Pappas AM. Congenital abnormalities of the femur and related lower extremity malformations: classification and treatment. J Pediatr Orthop 1983;3(01):45-60

15 Gillespie R, Torode IP. Classification and management of congenital abnormalities of the femur. J Bone Joint Surg Br 1983;65(05): 557-568

16 Paley D. Lengthening reconstruction surgery for congenital femoral deficiency. In: Herring JA, Birch JG, eds. The Child with a Limb Deficiency. Rosemont: American Academy of Orthopaedic Surgeons; 1998:113-132

17 Correll J, Baise M, Reinmann A. Proximal femoral focal deficiency. Orthop Proc 2018;85-B(supp_III):

18 Maldjian C, Patel TY, Klein RM, Smith RC. Efficacy of MRI in classifying proximal focal femoral deficiency. Skeletal Radiol 2007;36(03):215-220

19 Biko DM, Davidson R, Pena A, Jaramillo D. Proximal focal femoral deficiency: evaluation by MR imaging. Pediatr Radiol 2012;42 (01):50-56
20 Cuillier F, Cartault F, Moreau ML, Lemaire P. Antenatal presentation of isolated femoral hypoplasia discovered at 18 weeks of gestation. Fetal Diagn Ther 2005;20(03):197-202

21 Otera Y, Morokuma S, Yumoto Y, et al. Prenatal three-dimensional images of proximal focal femoral deficiency produced by helical computed tomography. Fetal Diagn Ther 2009;25(03):349-353

22 Lin $\mathrm{TH}$, Chung $\mathrm{CH}$, Shih JC, Lin $\mathrm{CH}$, Lee $\mathrm{CN}$, Su YN. Prenatal diagnosis of proximal femoral focal deficiency: a case report and literature review. Taiwan J Obstet Gynecol 2013;52(02): 267-269

23 Kudla MJ, Beczkowska-Kielek A, Kutta K, Partyka-Lasota J. Proximal femoral focal deficiency of the fetus - early 3D/4D prenatal ultrasound diagnosis. Med Ultrason 2016;18(03):397-399

24 Özdemir M, Kavak RP, Ceylan AH, Cevval ZK. Isolated unilateral proximal focal femoral deficiency presenting in a young woman. BMJ Case Rep 2020;13(01):e232714

25 Uduma FU, Dim EM, Njeze NR. Proximal femoral focal deficiency a rare congenital entity: two case reports and a review of the literature. J Med Case Reports 2020;14(01):27

26 Ellul M, Chircop M, Grixti C, Grech V. Proximal femoral focal deficiency - a case report. Malta Med J 2008;20:42-43

27 Laor T, Kan JH. Congenital abnormalities of bones. In: Coley BD, Bates DG, Faerber EN, et al, eds. Caffey's Pediatric Diagnostic Imaging. 12th ed Philadelphia, PA: Elsevier; 2013:1356-1369

28 Silvas E, Rypens F, Jovanovic M, Delezoide AL, Patey N. Prenatal diagnosis of femoral-facial syndrome: report of two cases. Birth Defects Res A Clin Mol Teratol 2013;97(12):770-773

29 Geipel A, Berg C, Germer U, Krokowski M, Smrcek J, Gembruch U. Prenatal diagnosis of femur-fibula-ulna complex by ultrasound examination at 20 weeks of gestation. Ultrasound Obstet Gynecol 2003;22(01):79-81

30 Gupta N, Kabra M. Limb/pelvis-hypoplasia/aplasia syndromefurther delineation of phenotype. Fetal Pediatr Pathol 2011;30 (06):355-358

31 Gupta SK, Alassaf N, Harrop AR, Kiefer GN. Principles of rotationplasty. J Am Acad Orthop Surg 2012;20(10):657-667

32 Paley D, Guardo F. Lengthening reconstruction surgery for congenital femoral deficiency. In: Kocaoglu M, Tsuchiya H, Eralp L, eds. Advanced Techniques in Limb Reconstruction Surgery. Berlin, Germany: Springer-Verlag; 2014:245-98 